\title{
Russell's revenge: a problem for bivalent Fregean theories of descriptions
}

\author{
Jan Heylen
}

\begin{abstract}
Fregean theories of descriptions as terms have to deal with improper descriptions. To save bivalence various proposals have been made that involve assigning referents to improper descriptions. While bivalence is indeed saved, there is a price to be paid. Instantiations of the self-predication scheme, viz. the one and only individual that is F is F, are not only allowed but even required to have different truth values, even if the relevant property is logically contingent.
\end{abstract}

Keywords. Descriptions; Russell; Frege; Carnap; Strawson; bivalence; self-predication.

\section{Introduction}

Definite descriptions are sometimes aligned with quantifiers (Russell, 1905; Sharvy, 1969; Barwise and Cooper, 1981; Neale, 1990), predicates (Fara, 2001), variables (Heim, 1982; Santorio, 2013) or complex terms (Frege, 1892; Carnap, 1956; Kalish and Montague, 1964; Lambert, 2003; Smith, 2003; Garson, 2006). ${ }^{1}$ The latter remains a popular option among philosophical logicians for various reasons. Smith $(2003,347)$ summarizes his case as follows:

In a language which has functions, we could introduce a 1-operator (read 'the') that takes us from an $n+1$-place predicate to a corresponding $n$-place function. Arguably, the vernacular descriptionforming operator 'the' works similarly.

Yet theories of descriptions as terms have to face problems regarding improper descriptions, i.e. descriptions for which the existence condition or the uniqueness condition are not satisfied. One puzzle Russell drew attention to is the apparent failure of the law of excluded middle in the case of subject-predicate sentences with improper descriptions. Here is the puzzle in his own words:

By the law of excluded middle, either 'A is B' or 'A is not B' must be true. Hence either 'the present King of France is bald' or 'the present King of France is not bald' must be true. Yet if we enumerated the things that are bald, and then the things that are not bald, we should not find the present King of France in either list. Hegelians, who love a synthesis, will probably conclude that he wears a wig. (Russell, 1905, 223)

Nevertheless there are bivalent Fregean theories of descriptions, which do not succumb to the problem noted by Russell. Notwithstanding that initial success I will argue in what follows that the problem posed by improper description terms runs deeper than was hitherto realized.

In Section 2 I give an overview of the various bivalent Fregean theories of descriptions. In Section 3 I introduce and discuss an important description principle, viz. self-predication. In Section 4 I present and discuss problems with some of the Fregean theories that have been noted in the literature. These problems depend tacitly on self-predication. I will argue in Section 5 that one of these problems extends to the other bivalent Fregean theories as well.

\footnotetext{
${ }^{1}$ For overviews of several options see (Linsky, 2011) and (Ludlow, 2013).
} 


\section{Bivalent Fregean theories of descriptions}

There are two important Fregean bivalent theories of definite descriptions as terms or, rather, two classes of such theories. ${ }^{2}$ First, there are versions of Fregean classical logic with descriptions - see (Pelletier and Linsky, 2005) for a detailed exposition. One version goes back to Frege (1892), Carnap (1956) and Kalish and Montague (1964). Sometimes I will refer to this theory as the Frege-Carnap theory, but for reasons that will become clear I will sometimes refer to it as the maximal Fregean Classical logic for description terms. The reference clause for description terms is the following:

FC-max if some individual $d$ belonging to the domain of quantification $D$ uniquely satisfies $\phi(x)$, then $x \phi \phi(x)$ refers to $d$; otherwise $x x \phi(x)$ refers to a designated individual $d^{*}$ in $D$.

It is convenient to single out an individual constant, $c^{*}$, that refers to $d^{*}$.

To see where the stipulation for improper descriptions is coming from it is instructive to think again about functions and, in particular, partial functions, i.e. functions that have only been defined for a proper subset of the domain of quantification. A common strategy to deal with them is to turn them into total functions (i.e. functions that have been defined for the entire domain of quantification) by giving an arbitrary stipulation for the function values when the arguments belong to the rest of the quantification domain. This is illustrated by Smith $(2003,344)$ as follows.

[Partial functions] abound in mathematics: to take the simplest case, the division function doesn't deliver a value everywhere (there is no output when you divide a number by zero). [...] However, can't we just (as it were) fill up the gaps in a partial function by arbitrary stipulation? For example, we could define the total division* function, where $m$ divided by $n$ is the same as $m$ divided by $n$ when $n>0$, and is equal to (say) 0 when $n$ is 0 .

Carnap's strategy to deal with improper descriptions is basically the same as the one used for partial functions.

Another version goes back to Frege (1893). The basic thought is that an improper description refers to the set of things that satisfy the descriptive condition. If the existence condition is not satisfied, then the description refers to the empty set. If the uniqueness condition is not satisfied, because two individuals satisfy the descriptive condition, then the description refers to the set of two things that satisfy the descriptive condition. E.g., 'the world cup won by the national team of Germany' refers to the set of four world cups won by that team. I will return to this version below.

Second, there are versions of Fregean positive free logic with descriptions - see (Lehmann, 2002) for a detailed exposition. One version is the minimal Fregean Free logic with descriptions The semantics presupposes that the domain $D$ is partitioned in an 'inner domain', $D_{i}$, and an 'outer domain', $D_{o}$. Bound variables range only over $D_{i}$. The extension of an $n$-place predicate belongs to $D^{n}$, so it may include individuals from the outer domain. The reference clause for description terms is the following:

FF-min if some individual $d$ belonging to the inner domain of quantification $D_{i}$ uniquely satisfies $\phi(x)$, then $x \phi(x)$ refers to $d$; otherwise $x \phi \phi(x)$ refers to some object $d$ belonging to $D_{o}$.

The minimal Fregean Free logic with descriptions is minimal, because there are no restrictions on assignments of referents of improper descriptions. The maximal Fregean Free logic with descriptions stipulates that all improper descriptions terms have the same referent. The outer domain can then consist of just one individual.

FF-max if some individual $d$ belonging to the inner domain of quantification $D_{i}$ uniquely satisfies $\phi(x)$, then $x \phi(x)$ refers to $d$; otherwise $x \phi(x)$ refers to $d^{\star}$, with $D_{o}=\left\{d^{\star}\right\}$.

\footnotetext{
${ }^{2}$ Each of the theories mentioned in this section has its own way of dealing with improper descriptions. Another theory, known as the Frege (1892)-Hilbert and Bernays (1934) theory, exclusively deals with proper descriptions. See (Pelletier and Linsky, 2005; Linsky, 2011) for more details.
} 
In between the minimal and the maximal Fregean Free theories lie multiple theories that impose constraints on the assignment of referents to improper descriptions, e.g. the referent of 'the individual that is identical to $t^{\prime}$ has to be identical to the referent of $t$.

One may wonder whether there is also a minimal Fregean classical logic with descriptions, with the following reference clause:

FC-min if some individual $d$ belonging to the domain of quantification $D$ uniquely satisfies $\phi(x)$, then $x x \phi(x)$ refers to $d$; otherwise $x x \phi(x)$ refers to some object belonging to $D$.

As in Fregean Free logic with descriptions, there are no restrictions on the assignments of referents to improper descriptions. The Frege-Carnap theory encountered earlier is maximal in just the same way as the maximal Fregean free logic with descriptions is. To the best of my knowledge nobody proposed a theory as weak as minimal Fregean free logic with descriptions. However, it is easy to see that Frege (1893)'s proposal is intermediate in that it requires an infinite domain, which has to contain sets, and restrictions on assignments of referents to improper descriptions. ${ }^{3}$

By way of illustration, let me briefly explain how the mentioned theories solve Russell's puzzle about improper descriptions and bivalence. According to classical Fregean logics with descriptions, an improper description refers to the designated individual $d^{*}$ or, more generally, some selected individual $d$ in the domain. Either $d\left(^{*}\right)$ is in the extension of the predicate 'is bald' or it is not. So, the law of excluded middle does not fail. In fact, Kaplan (1972) notes that 'the king of France is bald' may well be true, e.g. when $d^{*}$ is Yul Brynner. According to the Fregean free logics with descriptions, an improper description refers to some individual in the outer domain, say $d$. Either $d$ is in the extension of the relevant predicate or it is not. Hence, the law of excluded middle is saved again.

In this section I have looked at bivalent Fregean theories of descriptions. Left out is a bivalent but non-Fregean theory of description terms, viz. Russellian negative free logic with descriptions. In this theory the reference clause for descriptions is the following:

RF if some individual $d$ belonging to the domain of quantification $D$ uniquely satisfies $\phi(x)$, then $x x \phi(x)$ refers to $d$; otherwise, $x \phi \phi(x)$ does not refer. ${ }^{4}$

Since the extension of $n$-place predicates belongs to $D^{n}$, atomic sentences with improper descriptions are false - hence, negative free logic. See (Kalish et al., 1980) and (Lehmann, 2002) for details. Also left is non-bivalent logic with descriptions, e.g. the Frege (1892)-Strawson (1950) theory according to which subject-predicate sentences with improper description terms do not have a truth value. In this theory the reference clause for descriptions is the same as in the Russellian free logic with descriptions. The truth of atomic, subject-(simple) predicate sentences is given its classical definitional clause, but the falsity of the same kind of sentences is defined differently: an atomic sentence is false if and only if the referents of the terms in the sentence are defined but the tuple of referents of the terms in the sentence does not belong to the extension of the predicate. This leaves room for atomic sentences being neither true nor false, namely when at least one of the description terms in the atomic sentence is improper. There are various options for how to deal with complex sentences that contain improper description terms. One option is that all complex sentences with at least one improper description are neither true nor false.

In the next section I will introduce an important description principle and I will discuss how the various theories of descriptions deal with it.

\footnotetext{
${ }^{3}$ Pelletier and Linsky $(2005,236)$ note that there is a set-theoretic problem with Frege (1893)'s proposal, which I will ignore here. The main point is that different improper descriptions can have different referents in the outer domain.

${ }^{4} \mathrm{~A}$ trick used in (Pelletier and Linsky, 2005, 228) is to let an improper description refer to the domain of quantification $D$ itself. Since $D$ is not an element of $D$, the referent of an improper description does then not belong to the extension of a primitive predicate.
} 


\section{Descriptions and self-predication}

A striking property of definite descriptions is that they contain information about their referents (if any). For instance, 'the teacher of Alexander the Great' contains information about its referent, viz. Aristotle. A natural idea is then to construct a logical theory for definite descriptions that contains the following principle (Linsky, 2011, p. 80): ${ }^{5}$

1. $\phi(x x \phi(x))$.

The above principle has been dubbed 'self-predication principle' by Heylen (2010a). ${ }^{6}$ Examples of the above self-predication principles are the following:

2. The teacher of Alexander the Great is a teacher of Alexander the Great.

3. The pupil of Plato and teacher of Alexander the Great is a teacher of Alexander the Great.

The first example is a straightforward instantiation of (1), whereas the second example is a direct logical consequence of an instantiation of (1).

That self-predication is part of our natural logic of descriptions can be seen from the fact that it has been used by several philosophers throughout history. Anselm also seems to rely on it in his ontological argument: the combination of the description 'the thing that is conceivable and that is such that there is no thing that is both greater and conceivable' and the predicate 'is a thing that is conceivable and that is such that there is no thing that is both greater and conceivable' expresses a truth - see the reconstruction in (Oppenheimer and Zalta, 1991). Self-predication is also implicitly present in Frege's work:

In the case of genuinely proper names like 'Aristotle' opinions as regards their sense may diverge. As such may, e.g., be suggested: Plato's disciple and the teacher of Alexander the Great. Whoever accepts this sense will interpret the meaning of the statement 'Aristotle was born in Stagira' differently from one who interpreted the sense of 'Aristotle' as the Stagirite teacher of Alexander the Great. (Frege, $1949,86)$

In other words, there is an epistemological distinction between the following two sentences:

4. The Stagirite teacher of Alexander the Great was born in Stagira.

5. The disciple of Plato and the teacher of Alexander the Great was born in Stagira.

In epistemological terms, the first sentence is in a sense a priori knowable, whereas the second sentence is not. But there also seems to be a difference in logical status: the last sentence is logically contingent, whereas the first sentence is at first sight a logical truth.

The self-predication principle may be natural, but as Russell $(1905,483)$ showed, it is also naive. For instance, one can deduce the following instance of them:

6. The round square is both round and square.

Thus, principle (1) is inconsistent.

Nevertheless, even Russell acknowledges that self-predication is correct when the relevant descriptions are proper or, more formally, the following must be true:

7. $\exists x ! \phi(x) \rightarrow \phi(x x \phi(x))$,

\footnotetext{
${ }^{5}$ Here and throughout the text predicates are always assumed to express extensional properties. For more on what happens if one allows intensional predicates, see (Føllesdal, 2004; Martí, 1994; Kremer, 1997; Horsten, 2009; Heylen, 2010a,b).

${ }^{6}$ In Plato's work one sees adherence to another kind of self-predication, viz. the Form of F is F, e.g. the Just is just - see (Pelletier and Zalta, 2000) for details.
} 
with ! $\phi(x)$ an abbreviation for $\phi(x) \wedge \forall y(\phi(y) \rightarrow y=x)$. Indeed, if there is a unique round square, then it is round and square. In the formulation of (7) I am careless about scope, since in extensional contexts scope differences are immaterial when the description is proper (Whitehead and Russell, 1962; Kripke, 2005; Grabmayer et al., 2011). With Russell's scope indicator notation (7) can be reformulated as:

8. $\exists x ! \phi(x) \rightarrow[x x \phi(x)] \phi(\imath x \phi(x))$

where $[x x \phi(x)]$ is the relevant scope indicator. Russell also endorsed the following self-predication principle in the case of improper descriptions:

$$
\text { 9. } \neg \exists x ! \phi(x) \rightarrow \neg[x x \phi(x)] \phi(\neg x \phi(x)) .
$$

On Russell's view, if there is not a round square, it is not the case that the round square is square. Note that here scope does matter. Russell accepts (9), where the negation operator has wide scope, but not

$$
\text { 10. } \neg \exists x ! \phi(x) \rightarrow[x x \phi(x)] \neg \phi(x x \phi(x)),
$$

where the negation operator has narrow scope. Indeed, in Russell's theory the consequent of (10) is contradictory.

The bivalent Fregean theories of descriptions all agree on (7), in which the description term is proper. If one wants to use a device indicating the scope of the term-forming operator $\imath{ }^{7}$ then a natural choice is the lambda operator $\lambda$, which is a complex predicate-forming operator. For individual constants $c$, one lays down the following conversion rule: $\lambda x \phi(x)(c)$ if and only if $\phi(c / x)$ (Carnap, 1956, p. 3). With the help of the lambda operator one can formulate the self-predication principle as follows:

$$
\text { 11. } \lambda x \phi(x)(\imath x \phi(x)) \text {. }
$$

If $x \phi(x)$ is a proper description term, then (11) is sound according to every one of the theories presented in Section 2. The picture changes when $x \phi(x)$ is an improper description term. On the Frege-Strawson theory all instances of (11) with improper descriptions are without truth-value. On the Russellian negative free logic of descriptions all instances of (11) with improper descriptions are false. Both theories give a uniform treatment of instances of (11) with improper description terms. This is not the case for the bivalent Fregean theories of descriptions. As Kaplan (1972) observed about the Frege-Carnap theory, "the bald king of France is bald' may be true, if Yul Brynner is the chosen referent for improper descriptions. But it is equally the case that 'the bald king of France is bald' may be false, if Charlton Heston is the chosen referent. As Russell's argument shows, not all instances of (11) can be true on the pain of inconsistency, and the bivalent Fregean theories of descriptions are consistent. Additionally, not all instances of (11) can be false according to those theories. Indeed, the following instance has to be true on any of the bivalent Fregean theories:

12. The thing that is self-identical is identical to itself.

On the assumption that there are at least two things in the domain of quantification, "the thing that is self-identical' is an improper description. Still, (12) is true, because whatever referent that is assigned to the description term will be identical to itself.

What to do with self-predication in the case of improper descriptions is going to play an important role in the next section.

\footnotetext{
${ }^{7}$ Not all of the theories make use of a scope indicating device. Sometimes preference is given to a scope convention, in particular the convention that states that description terms should always be assigned the smallest possible scope - see (Carnap, 1956; Føllesdal, 2004; Martí, 1994; Kremer, 1997; Heylen, 2010a) for discussion of that scope convention for Carnap's theory.
} 


\section{Self-predication and maximal Fregean theories}

Let us have a look at three problems with maximal Fregean theories that have been noted in the literature. I will argue that self-predication plays an implicit role in two of these problems. The first problem is a counterexample to the Frege-Carnap theory and it is due to Lehmann $(2002,240)$ :

13. Zero is the non-self-identical number.

The above is true if the chosen referent is zero, a choice recommended by Carnap $(1956,36)$. The above is only problematic, because we tacitly assume the following instance of self-predication:

14. The non-self-identical number is not-self-identical.

Since zero is like all numbers a self-identical number, (13) and (14) clash with the substitutivity scheme. The second problem is a counterexample to the maximal Fregean Free logic and it is due to Nolt (2014, Subsection 5.1):

15. The golden mountain is a possible object

16. The set of all non-self-membered sets is a possible object.

Indeed, according to the theory under consideration the golden mountain and the set of all non-selfmembered sets are the same thing. According to the substitutivity scheme, (16) follows then from (15). Yet, it is tacitly assumed that the following instances of self-predication are correct:

17. The golden mountain is a golden mountain.

18. The set of all non-self-membered sets is a non-self-membered set.

It is a set-theoretical-cum-metaphysical consequence of (18) that the set of all non-self-membered sets is an impossible object, whereas it is a metaphysical consequence of (15) that the golden mountain is a possible object. Contradiction.

In this article I want to focus on extensional predicates, so the predicate expressing the property of being a possible object falls outside the scope of this article. Still, the line of criticism found in (Lehmann, 2002) and (Nolt, 2014) does not hinge on non-extensional predicates. However, the counterarguments do depend on the truth of certain instances of self-predication. As claimed at the end of Section 3, according to the Frege-Carnap theory 'the bald king of France is bald' is false if Charlton Heston is the chosen referent of improper description terms. Something similar can be said about the maximal Fregean Free logic of descriptions. Hence, the defenders of maximal Fregean theories of descriptions have the option of denying the instances of self-predication on which the counterarguments depend. In fact, they have to deny (14) and (16) on logical and set-theoretical grounds.

A second problem with the Frege-Carnap theory goes back to Neale (1995, p. 798-802). He starts from an intuitive inference rule, a so-called 'conversion rule', which he takes from Gödel (1944). Let $c$ be an individual constant and let $P$ be a monadic predicate. Then the rule is the following:

19. $P c$ if and only if $c=x(x=c \wedge P x)$.

Now suppose that $c$ is co-extensional with $c^{*}$, i.e. it refers to $d^{*}$. Then the right-to-left direction is not valid. For in the case that $P c$ is false, $x(x=c \wedge P x)$ is an improper description and it has to refer to $d^{*}$ and, therefore, be co-extensional with $c$. Neale $(1995$, p. 798$)$ concludes that 'I [Neale] am inclined to think that this finished off the treatment once and for all'. Note that the right-hand side of the conversion rule is an instance of self-predication, i.e. 'the individual that is $c \ldots$ is $c$ '. Furthermore, it is clear that the problem extends to maximal Fregean Free Logic as well. It is an interesting argument and I will come back to it.

A third problem with the Frege-Carnap theory was noted by Heylen (2010a, 365-366). The following are facts: 
20. There is no king of France.

21. There is no president of England.

22. Everything is either just or unjust, but not both.

Perhaps one has doubts about (22), but here 'unjust' is assumed to mean 'not just', with 'not' meaning classical negation. ${ }^{8}$ Importantly, negation has small scope here. Consider the following two sentences:

23. The just king of France is just.

24. The unjust president of England is unjust.

Both (23) and (24) are instances of the self-predication scheme (11). Given the fact that (23) and (24) are both instantiations of self-predication scheme, an attractive principle is the following:

25. It ought to be the case that (23) and (24) have the same truth-value. ${ }^{9}$

The implicit idea is that self-predication with descriptions is part of our natural, naive logic of descriptions and instances of it should be treated as uniformly as possible. Theories that satisfy this prescription have an important theoretical virtue. Recall that it was explained in Section 3 that Russell's theory of descriptions, the Russellian, positive free logic of descriptions and the Frege-Strawson theory do just that. According to the first two, (23)-(24) are false, whereas they are without truth-value according to the last theory.

The Frege-Carnap theory represents a different view. Since (20) and (21) are true, 'the just king of France' and 'the unjust president of England' refer to $d^{*}$, the object chosen as referent for improper descriptions. Moreover, since (22) is true, $d^{*}$ is either just or unjust, but not both. If $d^{*}$ is just, then (23) is true and (24) is false. If $d^{*}$ is unjust, then (23) is false and (24) is true. Not only is it permissible on the Frege-Carnap theory to assign different truth-values to (23) and (24), it is even obligatory to assign different truth-values to (23) and (24). That is, the Frege-Carnap theory satisfies the contrary of (25):

26. It ought to be the case that (23) and (24) have different truth-values.

So, not only does the Frege-Carnap theory allow to treat instances of scheme (11) differently, it even makes it mandatory to do so. Clearly, the above is also a problem for the maximal Fregean Free logic with descriptions. If there is only one individual in the outer domain of quantification, then either (23) is true and (24) is false, or the other way around.

To get a better appreciation of the principles involved, consider the following two sentences:

27. The thing that is self-identical is identical to itself.

28. The thing that is distinct from itself is distinct from itself.

Both (27) and (28) are instantiations of scheme (11), so it seems again eminently reasonable to accept the following analogue of (25):

29. One ought to assign the same truth-value to (27) and (28).

\footnotetext{
${ }^{8}$ In (Heylen, 2010a, 365) the predicates 'bald' and 'hairy' are used. They are supposed to be mutually exclusive and jointly exhaustive. I have opted for 'just' and 'unjust' to make the opposition more explicit. Alternatively, one could work with a restricted domain of quantification, i.e. the set of natural numbers, and use predicates that are mutually exclusive and jointly exhaustive for the restricted domain, i.e. 'odd' and 'even'.

${ }^{9}$ In (Heylen, 2010a, 365) the prescription is formulated in terms of accepting both sentences or rejecting both sentences the sentences rather than assigning them the same truth values. This kind of talk is a bit misleading if one can only accept or reject something on the basis of evidence.
} 
Both descriptions are improper. The uniqueness condition for the first description is not satisfied, assuming that there are at least two things. The existence condition for the second description is not satisfied. According to the Frege-Carnap theory, (27) is true and (28) is false. However, (29) is less plausible than (25). After all, on the Frege-Carnap theory there is a good reason to countenance (27) true and (28) false, whereas there is no such reason in the case of (23) and (24). Indeed, on the Frege-Carnap theory all statements of the form $t=t$ and, in particular $c^{*}=c^{*}$, are logically true and all statements of the form $t \neq t$ and, in particular $c^{*} \neq c^{*}$, are logically false, so here there is a systematic differential approach to self-predication. It is not unreasonable to grant the contrary of (29) to the Frege-Carnap theory:

30. One ought to assign different truth-values to (27) and (28).

In contrast, there is no systematicity lurking beneath the differential treatment of (23) and (24). In fact, one is forced to make distinctions where one can make only arbitrary distinctions, despite the fact that it involves instances of a natural logical scheme. In what follows it would be better to make exclusive use of logically contingent properties in order to be forthcoming to Fregeans.

Unlike the arguments by Lehmann (2002) and Nolt (2014) the argument by Heylen (2010a) cannot be undermined by denying the truth of particular instances of self-predication. Moreover and again in contradistinction with Lehmann (2002) and Nolt (2014), the argument does not involve logically or mathematically necessary or impossible predicates, such as 'is self-identical', 'is round and square', 'is not-self-identical', 'is a non-self-membered set' - see (6), (12), (14) and (18). What remains to be done is to see whether the problem extends to minimal Fregean theories as well. The same has to be done for the problem noted by Neale (1995).

\section{Self-predication and minimal Fregean theories}

Neither the argument given in (Neale, 1995) nor the argument developed in (Heylen, 2010a) is a problem for the minimal Fregean Free logic with descriptions. Let us consider these in turn.

There many things between heaven and earth and, likewise, there are many theories in between the maximal Fregean logic and the minimal Fregean logic. One such theory is the one that makes $c=$ $x(x=c)$ a logical truth (Lehmann, 2002, 243). Similarly, one could lay down the following stipulation: if $c$ refers to some object $d$ belonging to the outer domain $D_{o}$, then $d$ belongs to the extension of $P$ if and only if $x x(x=c \wedge P x)$ refers to $d$. If the outer domain contains at least two elements, then it is easy to satisfy the stipulation. In case the referent of $c$ does not belong to the extension of $P$, let the description $x(x=c \wedge P x)$ refer to the other element. Going from simple subject-predicate sentences, viz. $P c$, to more complex sentences (without description operators) $\phi(c)$ is not going to help much. In case $\phi(c)$ is false, let the description $x(x=c \wedge \phi(x))$ refer to the other element. It looks like the problem noted by Neale (1995) has no potential for undermining less-than-maximal Fregean theories of descriptions.

Let us return now to the third problem discussed in Section 4. All one has to do avoid violating (25) is to assign to 'the unjust president of England' an element from the outer domain that is different from the one assigned to 'the just king of France'. Of course, an outer domain with just two elements will not do either. Consider the following definite descriptions:

$$
\begin{aligned}
& t_{1} \text { : The just, wise king of France } \\
& t_{2} \text { : The just, unwise king of France } \\
& t_{3} \text { : The unjust, wise president of England } \\
& t_{4} \text { : The unjust, unwise president of England }
\end{aligned}
$$

Here 'unwise' is assumed to mean 'not wise', with 'not' meaning classical negation. With this meaning fixed it follows that: 
31. Everything is either wise or unwise, but not both.

Unless $t_{1}$ and $t_{2}$ refer to different individuals, either ' $t_{1}$ is wise' is true and ' $t_{2}$ is unwise' is false, or ' $t_{1}$ is wise' is false and ' $t_{2}$ is unwise' is true. Unless $t_{1}$ and $t_{3}$ refer to different individuals, either ' $t_{1}$ is just' is true and ' $t_{3}$ is unjust' is false, or ' $t_{1}$ is just' is false and ' $t_{3}$ is unjust' is true. Unless $t_{1}$ and $t_{4}$ refer to different individuals, either ' $t_{1}$ is just' is true and ' $t_{4}$ is unjust' is false, or ' $t_{1}$ is just' is false and ' $t_{4}$ is unjust' is true. I leave the rest of the argument as an exercise for the reader. The upshot of the argument is that one needs at least four individuals in the outer domain, provided one wants to treat the relevant instances of (11) equivalently. This argument can be generalised to finite outer domains, but it is not effective if the outer domain is infinite. Yet there is still a version of the problem that works against the minimal Fregean Free logic with descriptions, even if one allows only infinite outer domains.

Previously I made use of monadic predicates, now I will make use of a dyadic predicate. Moreover, up until now I have made use of predicates with no description terms as arguments. Consider 'the legitimate son of the emperor of Germany'. There is none. Next, consider the following four description terms:

$t_{5}$ : The just king of France who is the legitimate son of the emperor of Germany

$t_{6}$ : The unjust king of France who is the legitimate son of the emperor of Germany

$t_{7}$ : The just president of England who is not the legitimate son of the emperor of Germany

$t_{8}$ : The unjust president of England who is not the legitimate son of the emperor of Germany

Now consider the following four sentences:

32. The just king of France who is the legitimate son of the emperor of Germany is the legitimate son of the emperor of Germany.

33. The unjust king of France who is the legitimate son of the emperor of Germany is the legitimate son of the emperor of Germany.

34. The just president of England who is not the legitimate son of the emperor of Germany is not the legitimate son of the emperor of Germany.

35. The unjust president of England who is not the legitimate son of the emperor of Germany is not the legitimate son of the emperor of Germany.

Suppose that they all have the same truth value. For instance, (32)-(35) are all true. Then the following two sentences have different truth values:

36. The just king of France who is the legitimate son of the emperor of Germany is just.

37. The unjust king of France who is the legitimate son of the emperor of Germany is unjust.

If (32) and (33) are both true, then $t_{5}=t_{6}$ and identicals are substitutable, so (36) and (37) cannot be equivalent. If (32)-(35) are all false, then the following two sentences have different truth values:

38. The just president of England who is not the legitimate son of the emperor of Germany is just.

39. The unjust president of England who is not the legitimate son of the emperor of Germany is unjust.

If (34) and (35) are both false, then $t_{7}=t_{8}$ and identicals are substitutable, so (38) and (39) cannot be equivalent. The only other option is that not all of (32)-(39) have the same truth value. Either way, some instances of (11) are forced to have different truth values. Each of (32)-(39) is an instantiation of the general scheme (11). So, it would seem reasonable to impose that: 
40. One ought to assign the same truth values to (32)-(39).

Yet, both minimal Fregean free logic with descriptions and minimal Fregean classical logic with descriptions demand that some of (32)-(39) need to have different truth values. The predicates involved are logically contingent.

One part of the above argument can be seen as an extension of Lehmann (2002)'s argument. In the case of maximal Fregean theories, the identity between $t_{5}$ and $t_{6}$ is given, whereas in the case of minimal Fregean theories it is not. However, one can obtain that identity if one assumes the truth (32) and (33). The substitutivity scheme and the instances of self-predication (32)-(33), (36)-(37) together entail a contradiction.

The conclusion is that Fregean theories of descriptions, maximal and minimal, free and classical alike, do not allow to give the same truth-value to all instances of self-predication with improper descriptions and predicates expressing logically contingent properties. In Section 4 three problems with maximal Fregean theories of descriptions were discussed. All of these problems involve self-predication. It was remarked that the first problem, which was seen by Lehmann (2002) and Nolt (2014), left some room for manoeuvring by the Fregeans. In this section it was argued that the second problem, which was seen by Neale (1995), does not seem to have the potential to become a problem for the minimal Fregean theories as well. In contrast, the third problem, which was seen by Heylen (2010a), does have the potential to undermine the minimal Fregean theories.

\section{Conclusion}

Kuhn (1977) rightly remarked that there are multiple criteria for theory choice. The same applies to choice between theories of definite descriptions:

\footnotetext{
Theories of descriptions can therefore be seen as trying to account for our ordinary usage and for the usage in semi-formalized situations. In giving such a theory, one will feel tugs from different directions: on one side is the grammatical tug, which encourages the theoretician to mirror the syntactic features of these natural sentences when giving a theoretical account of descriptions. Another side tugs from "rationality", which would have the theoretician give a formal account that matches the intuitive judgments about validity of natural sentences when used in reasoning. And yet a third side tugs from considerations of scientific simplicity, according to which the resulting theoretical account should be complete in its coverage of all the cases but yet not postulate a plethora of disjointed subtheories. It should instead favor one overarching type of theoretical analysis that encompasses all natural occurrences with one sort of entity whenever possible so that the resulting system exhibits some favored sort of simplicity. (Pelletier and Linsky, 2005, 298)
}

Just as, say, matching intuitive judgements about the validity of arguments and simplicity are theoretical virtues of theories about definite descriptions, so is treating instances of self-predication schemes as uniformly as possible. After all, self-predication belongs to our natural logic of descriptions. Russell insightfully claimed that not all instances of self-predication can be true: self-predication with certain improper descriptions leads to inconsistency. His own theory of descriptions and the Russellian, negative free logic of descriptions impose falsehood on all instances of self-predication with improper descriptions. Likewise, non-bivalent Fregean free logic with descriptions, e.g. the Frege-Strawson theory, treats all simple instances of self-predication the same, viz. they are neither true nor false. (The various options for complex formulas make it difficult to give a general answer.)

The bivalent Fregean theories of descriptions have to countenance some instances of self-predication as true and some instances as false. These instances involve logically necessary or impossible predicates such as 'is self-identical' or 'is not-self-identical'. The bivalent Fregean theories allow one to assign different truth-values to instances of self-predication with logically contingent predicates, e.g. by assigning 
Yul Brynner to 'the bald king of France' and 'the hairy president of England'. This means that those theories lack the theoretical virtue shared by the other theories. But there is more to it: it is not only the case that those theories allow one to treat instances of self-predication with logically contingent predicates differently, they even impose it. This is a theoretical vice. It is shared by all bivalent Fregean theories, be they maximal or minimal, classical or free. To become virtuous again, it seems that Fregeans have to drop bivalence or adopt a more Russellian approach. Improper descriptions still pose a challenge for bivalent Fregean theories of description terms, notwithstanding the initial success in dealing with Russell's criticism. $^{10}$

Jan Heylen

Centre for Logic and Analytic Philosophy

Institute of Philosophy

KU Leuven

\section{References}

Barwise, J. and R. Cooper (1981). Generalized quantifiers and natural language.

Carnap, R. (1956). Meaning and Necessity (second ed.). Chicago: The University of Chicago Press.

Fara, D. G. (2001). Descriptions as predicates. Philosophical Studies 102, 1-42.

Føllesdal, D. (2004). Referential Opacity and Modal Logic. Routledge. Originally published as: Referential Opacity and Modal logic. Oslo: Universitetsforlaget, 1966.

Frege, G. (1892). Über Sinn und Bedeutung. Zeitschrift für Philosophie und Philosophische Kritik 100(1), 25-50.

Frege, G. (1893). Grundgesetze der Arithmetik, begriffsschriftlich abgeleitet, Volume 1. Jena: Verlag Hermann Pohle.

Frege, G. (1949). On sense and nominatum. In H. Fiegl and W. Sellars (Eds.), Readings in Philosophical Analysis, pp. 85-102. Appleton-Century-Crofts.

Garson, J. W. (2006). Modal Logic for Philosophers. Cambridge University Press.

Gödel, K. (1944). Russell's mathematical logic. In S. Feferman, J. Dawson, and S. Kleene (Eds.), The Philosophy of Bertrand Russell, pp. 119-141. Northwestern University Press.

Grabmayer, C., J. Leo, V. van Oostrom, and A. Visser (2011). On the termination of russell's description elimination algorithm. Review of Symbolic Logic 4(3), 367-393.

Heim, I. (1982). The Semantics of Definite and Indefinite Noun Phrases. Ph. D. thesis, UMass Amherst.

Heylen, J. (2010a). Carnap's theory of descriptions and its problems. Studia Logica 94(3), 355-380.

Heylen, J. (2010b). Descriptions and unknowability. Analysis 70(10), 50-52.

Hilbert, D. and P. Bernays (1934). Grundlagen der Mathematik, Volume I. Springer-Verlag.

\footnotetext{
${ }^{10}$ Earlier versions of this paper have been presented at Free University Brussels (Mini-Workshop on Modal Logic, May 12 , 2012), KU Leuven (CLAW Seminar, October 12, 2012), Bristol University (Logic PhD Seminar, Department of Philosophy, 17 June 2014). I would like to thank the participants for their feedback. I would also like to thank my colleagues Lorenz Demey and Harmen Ghijsen for their comments.
} 
Horsten, L. (2009). An argument concerning the unknowable. Analysis 69(2), 240-242.

Kalish, D. and R. Montague (1964). Logic: Techniques of Formal Reasoning. Harcourt, Brace \& World.

Kalish, D., R. Montague, and G. Mar (1980). Logic: Techniques of Formal Reasoning. Harcourt Brace Jovanovich.

Kaplan, D. (1972). What is Russell's theory of descriptions? In D. F. Pears (Ed.), Bertrand Russell: A Collection of Critical Essays, pp. 227-244. Anchor Books.

Kremer, M. (1997). Marti on descriptions in Carnap's S2. Journal of Philosophical Logic 26(6), 629-634.

Kripke, S. A. (2005). Russell's notion of scope. Mind 114(456), 1005-1037.

Kuhn, T. S. (1977). Objectivity, value judgment, and theory choice. In The Essential Tension, pp. 320-39. University of Chicago Press.

Lambert, K. (2003). Free Logic: Selected Essays. Cambridge University Press.

Lehmann, S. (2002). More free logic. In D. Gabbay and F. Guenthner (Eds.), Handbook of Philosophical Logic, Volume 5 of Handbook of Philosophical Logic, pp. 197-259. Springer Netherlands.

Linsky, B. (2011). Quantification and descriptions. In L. Horsten and R. Pettigrew (Eds.), The Continuum Companion to Philosophical Logic, pp. 77-104. Continuum.

Ludlow, P. (2013). Descriptions. In E. N. Zalta (Ed.), The Stanford Encyclopedia of Philosophy (Fall 2013 ed.).

Martí, G. (1994). Do modal distinctions collapse in Carnap's system? Journal of Philosophical Logic 23(6), 575-593.

Neale, S. (1990). Descriptions, Volume 43. Mit Press.

Neale, S. (1995). The philosophical significance of gödel's slingshot. Mind 104(416), 761-825.

Nolt, J. (2014). Free logic. In E. N. Zalta (Ed.), The Stanford Encyclopedia of Philosophy (Winter 2014 ed.).

Oppenheimer, P. E. and E. N. Zalta (1991). On the logic of the ontological argument. Philosophical Perspectives 5, 509-529.

Pelletier, F. J. and B. Linsky (2005). What is Frege's theory of descriptions? In B. Linsky and G. Imaquire (Eds.), On Denoting: 1905-2005, pp. 195-250. Munich: Philosophia Verlag.

Pelletier, F. J. and E. N. Zalta (2000). How to say goodbye to the third man. Noûs 34(2), 165-202.

Russell, B. (1905). On denoting. Mind 14(56), 479-493.

Santorio, P. (2013). Descriptions as variables. Philosophical Studies 164(1), 41-59.

Sharvy, R. (1969). Things. The Monist 53(3), 488-504.

Smith, P. (2003). An Introduction to Formal Logic. Cambridge University Press.

Strawson, P. F. (1950). On referring. Mind 59(235), 320-344.

Whitehead, A. N. and B. Russell (1962). Principia Mathematica, to *56. Cambridge University Press. 